\title{
The Billion Oyster Project and Curriculum and Community Enterprise for Restoration Science Curriculum Impact on Underrepresented Student Motivation to Pursue STEM Careers
}

\author{
Lauren B. Birney ${ }^{1, *}$, Brian R. Evans ${ }^{1}$, Joyce Kong ${ }^{1}$, Vibhakumari Solanki ${ }^{2}$, Elmer-Rico Mojica ${ }^{3}$, Christelle Scharff ${ }^{4}$, \\ Dimitrios Kaoutzanis ${ }^{5}$ \& Gaurav Kondapuram ${ }^{5}$ \\ ${ }^{1}$ School of Education, Pace University, New York, New York, United States \\ ${ }^{2}$ NYC Department of Education New York, NY, United States \\ ${ }^{3}$ Dyson College of Arts and Sciences, Pace University, New York, New York, United States \\ ${ }^{4}$ Seidenberg School of CSIS, Pace University, New York, New York, United States \\ ${ }^{5}$ Pace University, New York, New York, United States \\ *Correspondence: School of Education, Pace University, New York, New York, United States. E-mail: \\ lbirney@pace.edu
}

Received: July 19, 2021

doi:10.5430/jct.v10n4p47
Accepted: September 30, $2021 \quad$ Online Published: November 15, 2021

URL: https://doi.org/10.5430/jct.v10n4p47

\begin{abstract}
The Billion Oyster Project and Curriculum and Community Enterprise for the Restoration of New York Harbor with New York City Public Schools (BOP-CCERS) program is a National Science Foundation (NSF) supported initiative and collaboration of multiple institutions and organizations led by Pace University. The NSF project, Innovative Technology Experiences for Students and Teachers (ITEST), had generated a large amount of data through engagement with teachers and students throughout New York City public schools. One purpose of this project is to engage with middle and high school science teachers to assist them in using project-based learning and real-world data collection in their classrooms with their students through harbor restoration initiatives. It was found that Underrepresented Minority (URM) students reported having higher levels of interest in STEM and science than did the non-URM students. While this is a success, it was found that the URM students had lower expectations for success in STEM courses and interest in STEM careers. It was concluded that URM students may need additional support in order to build their confidence and help them to become aware of opportunities in STEM education and careers.
\end{abstract}

Keywords: STEM education, underrepresented groups, engagement and motivation, field science, STEM career

\section{Introduction}

The Billion Oyster Project and Curriculum and Community Enterprise for the Restoration of New York Harbor with New York City Public Schools (BOP-CCERS) program is a National Science Foundation (NSF) supported initiative and collaboration of multiple institutions and organizations led by Pace University. The NSF project, Innovative Technology Experiences for Students and Teachers (ITEST), had generated a large amount of data through engagement with teachers and students throughout New York City public schools. One purpose of this project is to engage with middle and high school science teachers to assist them in using project-based learning and real-world data collection in their classrooms with their students through harbor restoration initiatives. BOP-CCERS uses a model that involves over 5600 of New York City's 1.1 million public school students.

Literature has reported the impact generated by STEM summer programs on student participants. Numerous summer programs for high school students offer research projects in different STEM fields which is an effective strategy of showing real life relevance of STEM to increase recruitment of student in science related careers (Kitchen, Sonnert, \& Sadler, 2018; Roberts et al., 2018; Rohrbaugh \& Corces, 2011; Salto et al., 2014). Many of these programs involve informal learning, peer learning, linkage with university, targeted career development activities, and mentoring by university students. The same results was also observed in a STEM summer program for middle school students where 
participants were exposed to informal learning and found the STEM content session to be fun and engaging to increase their motivation and interests in STEM fields (Mohr-Schroeder et al., 2014). These types of STEM activities (i.e., research projects and informal learning experiences) are crucial for STEM education since they provide authentic experience not only to the teachers but also to students. The activities involved in the BOP-CCERS (project-based learning activities with real life application) offer an opportunity for students, especially underrepresented minority (URM) students to be engaged in a community or citizen science project, and provide the opportunity to experience the excitement of scientific discovery. Although great effort has been done to improve the pipelines of the URM in the college level particularly in STEM degrees, more improvement can be done if the intervention starts earlier. It has been reported that many students entering the eighth grade found many of the STEM subjects to be too challenging, boring, and uninteresting (President's Council of Advisors on Science and Technology, PCAST, 2010) .

\section{Background and Context}

BOP-CCERS is by design, a model of community-based restoration science education that requires not only parental support of student learning, but direct large-scale participation by school community members in the practical, highly localized applications of restoration science. Every school engaged in the BOP-CCERS model, relies on a dedicated community of parents, volunteers and STEM $+\mathrm{C}$ professional working in concurrence on nearby reef restoration sites, collecting and sharing BOP-CCERS standardized field data, and providing new opportunities for student technical learning outside of the classroom. This broader community of parent-volunteers and STEM $+\mathrm{C}$ professionals involved in BOP-CCERS is a prime factor in driving the growth and expansion of the model across New York City schools. Over the past year alone, this broader community of restoration science practitioners has more than tripled in size, establishing the necessary resources on the ground to support the Phase II expansion of BOP-CCERS. Currently, BOP-CCERS curriculum and teacher training programs are being implemented in 78 Title I funded public schools and afterschool programs in New York City. At this level, the model engages more than 5,600 students directly on a weekly basis in hands-on restoration-based STEM activities in the classroom curriculum, through lab activities, and field expeditions. Beyond the immediate sphere of impact, 870+ volunteers engage annually at STEM Hubs and reef restoration sites in three low-income neighborhoods of coastal Brooklyn. More than 300 of these volunteers work directly with BOP-CCERS students in monitoring Oyster Research Stations and community reefs.

The result of the BOP-CCERS ITEST (Phase II) project is to create an innovative STEM curriculum for teachers that utilizes computational thinking and science; a meaningful, highly engaging basis of learning for students; and a unifying platform around which to engage a diverse community of STEM professionals, graduate and postdoctoral scientists, and educators in informal education settings in carrying out an array of complementary education and restoration activities.

The research question from the project was to determine the aspects of the BOP-CCERS project that had a positive influence on underrepresented students' motivation and preparation to pursue STEM careers, compared to other students. A key outcome is to encourage students from underrepresented backgrounds to pursue STEM courses and majors throughout their education, and hence pursue a STEM-based career. A major goal is to provide programming and educational experiences that motivate student interest in STEM that helps to diversify STEM careers in the United States.

\section{Theoretical Framework and Literature Review}

The theoretical framework for this study rests upon Bandura's $(1986,1997)$ self-efficacy and social cognitive theory through which students develop through their social interactions and the development of their self-efficacy. It is possible that self-efficacy is one of the more important variables for academic success, which is related to student engagement and persistence. Moreover, Vygotsky's sociocultural theory of learning (Vygotsky, 1987) provides grounding for this study in which teacher facilitators and students form a community of learners through their collaboration and connections. Thirdly, Piaget's constructivist theory of learning provides a foundation for student-centered exploration and investigation (Piaget, 1971; Piaget \& Inhelder, 1972), which is important for the development of knowledge, skills, and understanding in STEM education.

In an effort to increase Underrepresented Minority (URM) student participation in STEM courses, majors, and careers, it is important to provide students with real-world and engaging STEM activities. The BOP-CCERS project created opportunities for students to engage in hands-on and real-world STEM learning in the way that STEM professionals conduct their work. As indicated in the authors' recent publication, "Students learn science and mathematics through 
'doing' in the way scientists and mathematicians conduct their own research, investigations, and practices (Brandt, 2016; Hoskins, 2019; Plank, 2017; Wilcox, Cruse, \& Clough, 2015)” (Birney et al., 2021, p. 29). Moreover, "Not only do these experiences reflect the way in which STEM professionals conduct their work, but also they can be some of the most engaging and rewarding of a student's academic career (Mokter Hossain \& Robinson, 2012)" (Birney et al., 2021, p. 29). In the present study, the authors investigated the impact of the BOP-CCERS STEM activities on student engagement and motivation with focus on engaging Underrepresented Minority (URM) students.

Previous studies have found that students could potentially benefit from more active learning techniques and activities in STEM courses (Freeman et al., 2014), and in particular, Underrepresented Minority students (URM), which was found in a recent study at the University of Washington (Theobald et al., 2020). Moreover, Martin-Hansen (2018) found a strong STEM identity is a predictor of future STEM career choice, which was also one of the measurements used in this current study. Kennedy and Odell (2014) had emphasized interdisciplinary STEM connections for students, particularly through the use of STEM academies that emphasize technology integration and problem solving, in order to demonstrate the connections within the STEM disciplines.

Estrada et al. (2016) found the following five recommendations are helping to engage and diversity STEM: track and increase diversity awareness, create creative STEM partnerships, use curriculum and active learning, provide resources, and motivate creativity among students. Similarly, Preininger (2018) recommended the following four techniques: use of role models, growth mindset particularly for women in STEM, connections for math in non-quantitative classes, and project-based learning. These studies align closely to the strategies employed in the current ITEST study: scientific identity, engagement with scientists in the project, and use of STEM projects and activities.

\section{Methodology}

The design of study was through survey research conducted by the National Science Foundation (NSF) grant-funded research and evaluation firm, The Mark, which serves as consultant for the NSF project, Innovative Technology Experiences for Students and Teachers (ITEST). Students were in two groups: Underrepresented Minority (URM) students and non-URM. Survey questions measured motivation to pursue STEM careers (e.g., "I am interested in jobs related to science"), scientific identity (e.g., "I have a sense of belonging in a community of scientists"), engagement with scientists in the project, number of projects students on which students worked, and number of activities in which students engaged.

Students surveyed participated in community-based oyster restoration STEM Hubs, peer mentoring, the Summer STEM Institute, and curricular activities in STEM and computer science. Moreover, teachers engage in laboratory experiential learning preparation including field science and research protocols along with science content related to oyster habitat restoration and ecology of New York City waterways.

Middle and high school students are involved in field research, data science, and computer programming activities related to oyster reef restoration in New York Harbor. Students travel to the STEM Hubs at various waterfront sites throughout New York City to collect data on oyster growth and water quality. They have the opportunity to work with scientists to collect and discuss real time data while they are in the field. The data is then analyzed in the classroom setting and uploaded to a BOP-CCERS Digital Platform. The BOP-CCERS Digital Platform also serves as a place for teachers to access inquiry-based curriculum on restoration science. Teachers have the opportunity to download and provide feedback on lessons used.

Another component is the peer mentoring program. Younger students were paired with older students for oyster research mentoring and waterfront restoration activities at the STEM Hub sites. During the initial phase of the program, 11 th grade students participating in an afterschool program shared their experiences and knowledge with 9th graders as they explored maritime career options together. Prior to the school closures due to the COVID-19 pandemic, plans included students across the elementary, middle and high school levels. Once restrictions are lifted, it is hopeful that the current working model may be expanded to coordinate activities among more students.

High School students from the New York Metro Area participating in the Summer STEM Institute learn to analyze the BOP-CCERS data collected over time using Python programming. They work in teams to make use of BOP-CCERS data and gain real-world hands-on learning applications of technology and field research. Students created data models and used design thinking methodologies while learning about the Billion Oyster Project to restore a sustainable oyster population. During the Summer STEM Institute, students are also exposed to career-oriented panels and have opportunities to network with STEM undergraduate and graduate students along with industry professionals. 


\section{Results}

The measurements for the results and outcomes for the project were conducted by the National Science Foundation (NSF) grant-funded research and evaluation firm, The Mark, which serves as a research consultant for the NSF project, Innovative Technology Experiences for Students and Teachers (ITEST). The overarching question driving the research project is the following: What aspects of the BOP-CCERS project have a positive influence on underrepresented students' motivation and preparation to pursue STEM careers, compared to other students? This question was answered through survey data collection conducted with participants of the study.

The evaluation team surveyed 500 students who participated in the project for over two years and received 111 responses in return to have a response rate of approximately $22 \%$, which was considered to be an acceptable response rate. It was found that Underrepresented Minority (URM) students reported having higher levels of interest in STEM and science than did the non-URM students (see Figure 1). Students responded to survey questions on a Likert scale with ratings from $1=$ strongly disagree to $5=$ strongly agree, such as "I want to understand science" and "I like to see how things are made". The URM students had higher average interest $(\mathrm{M}=4.21, \mathrm{SD}=0.64)$ compared to the non-URM group $(=3.79, \mathrm{SD}=1.05)$ and students who did not report their $\mathrm{URM}$ status $(\mathrm{M}=3.97, \mathrm{SD}=0.92)$. While this is a success, it was found that the URM students had lower expectations for success in STEM courses and interest in STEM careers. It was concluded that URM students may need additional support in order to build their confidence and help them to become aware of opportunities in STEM education and careers.

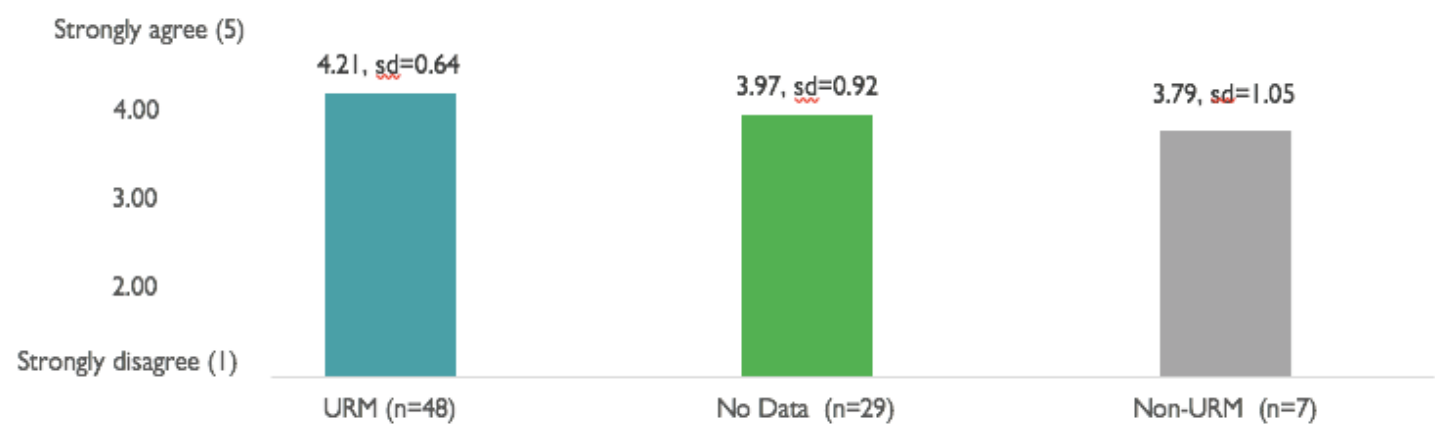

Figure 1. STEM Career Interest

URM students were found to have engaged in a greater number of STEM activities compared to non-URM students, but with less time in the activities. Participating in the project specific activities may help to close this gap and will require further study. Since URM students in the study had fewer family members or acquaintances who are scientists (see Figure 2), direct engagement with scientists in different activities can overcome the limited exposure or knowledge that they have about STEM careers (see Figure 3). URM students (26\%) reported they engaged in direct projects with scientists compared to non-URM students (29\%) and students who did not report their URM status (25\%). These findings indicate there is great potential this project may have on positively influencing URM students' motivation and preparation for STEM careers.

Overall, findings from the study were encouraging. URM students in the project have a lower expectation of success and interest in STEM careers. Thus, the BOP-CCERS project has the potential to improve URM student engagement and motivation in STEM. Moreover, the curricula and innovations designed by the project demonstrated that it will provide additional opportunities for students to learn about STEM through participating in STEM activities, engaging with scientists, and receiving guidance from mentors, which can help URM students and further enhance student engagement and motivation in STEM. As evidenced here on the BOP-CCERS Digital Platform, even in the time of the COVID-19 pandemic, students were able to engage in all activities in a remote/virtual environment which is now slowly returning to in person practices and events. 


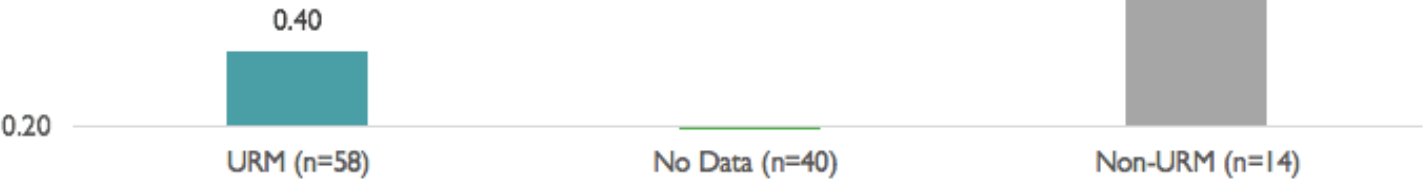

Figure 2. Family Members as Scientists

$100 \%$

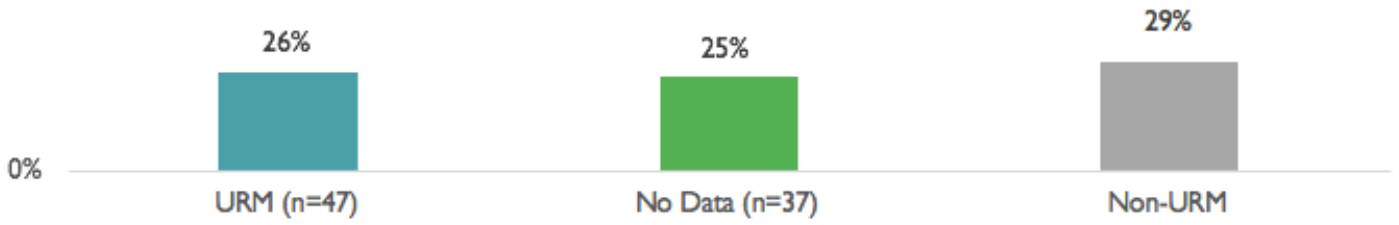

Figure 3. Direct Projects with Scientists

\section{Discussion and Conclusion}

BOP-CCERS is by design, a model of community-based restoration science education that requires not only parental support of student learning, but direct large-scale participation by school community members in the practical, highly localized applications of restoration science. Every school engaged in the BOP-CCERS model, relies on a dedicated community of parents, volunteers, and STEM $+\mathrm{C}$ professional working in concurrence on nearby reef restoration sites, collecting and sharing BOP-CCERS standardized field data, and providing new opportunities for student technical learning outside of the classroom. This broader community of parent-volunteers and STEM $+\mathrm{C}$ professionals involved in BOP-CCERS is a prime factor in driving the growth and expansion of the model across New York City schools. Over the past year alone, this broader community of restoration science practitioners has more than tripled in size, establishing the necessary resources on the ground to support the Phase II expansion of BOP-CCERS.

Currently, BOP-CCERS curriculum and teacher training programs are being implemented in 78 Title I funded public schools and afterschool programs in New York City. At this level, the model engages more than 5,600 students directly on a weekly basis in hands-on restoration-based STEM activities in the classroom curriculum, through lab activities, and field expeditions.

Beyond the immediate sphere of impact, 870+ volunteers engage annually at STEM Hubs and reef restoration sites in three low-income neighborhoods of coastal Brooklyn. More than 300 of these volunteers work directly with BOP students in monitoring Oyster Research Stations and community reefs.

Teachers in the BOP-CCERS program reported that they are better prepared to teach scientific research, oyster biology and ecological restoration. Students who engage in real-world science learning activities are more likely to see the relevance of science and see themselves working toward a STEM career pathway (Birney et al., 2019).

In BOP-CCERS Phase III STEM+ Computing through environmental restoration, this enhanced model will be implemented at an additional 10-14 Title I funded schools across New York City, including both middle school and high school classrooms. Due to the variety of population sizes in the New York City Department of Education middle and intermediate schools, this has the capacity to reach thousands of additional students who will be able to participate 
directly in the BOPS-CCERS field research-based curriculum as well as to enroll in long-term restoration science career and technical education pathways. This will enable an additional 15 to 20 thousand students to participate directly in the BOP-CCERS field research-based curriculum as well to enroll in long-term restoration STEM $+\mathrm{C}$ career and technical education pathways. Ultimately, the BOP-CCERS Model seeks to serve as a STEM $+\mathrm{C}$ Learning and Research Center whereby, local, global, and international scientists, researchers, academicians, teachers, students and $\mathrm{STEM}+\mathrm{C}$ industry professionals can actively engage, participate, conduct research and learn from the BOP-CCERS Model. This uniquely created STEM $+\mathrm{C}$ Learning Ecosystem focused upon creating opportunities for underrepresented in STEM $+\mathrm{C}$ education, has the capacity to continue to make a larger impact globally. Ultimately, creating and establishing public and private sector partnerships will allow for this entity to ultimately be self-sustaining and serve as a permanent STEM+C BOP-CCERS Learning Resource Ecosystem in New York City (see Figure 3).

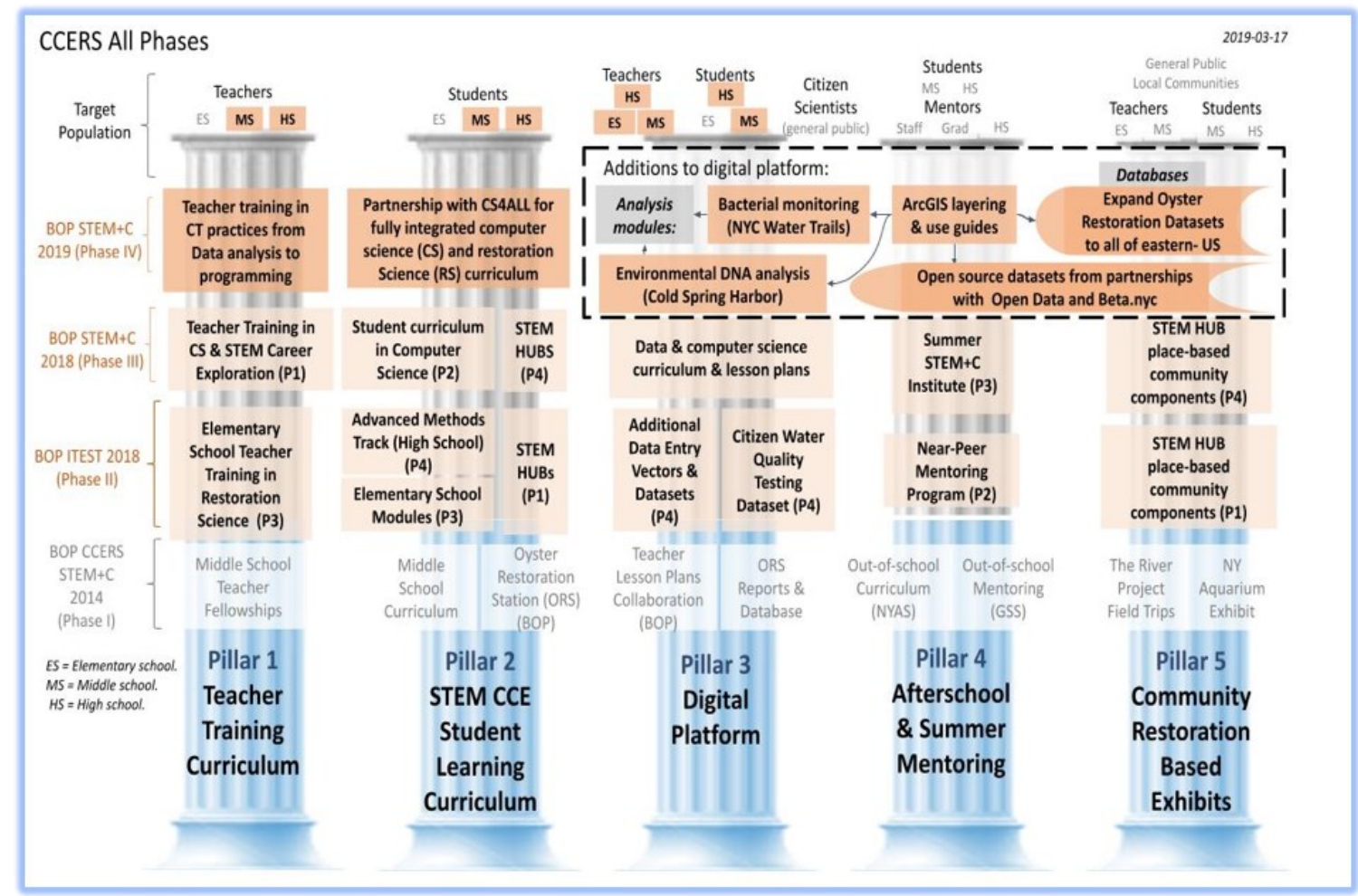

Figure 4. BOP-CCERS Pillars

There are two main limitations in this study. First, the disruptions from the COVID-19 pandemic created some complications with implementation and data collection that the research team was able to resolve, but should be mentioned as having a possible impact on the experiences and outcomes of the project. Secondly, the response rate of $22 \%$, while acceptable, was lower than the research team would have preferred. Additional efforts to collect data during the in-person activities and events are being implemented in the post-pandemic environment in order to get a better sense on the outcomes from the project. This process will continue in the longer term implementation of the project.

The findings in this study are important for supporting URM students in STEM courses, majors, and career pipelines. A purpose of this project is to engage with middle and high school science teachers to assist them in using project-based learning and real-world data collection in their classrooms with their students through harbor restoration initiatives. The result of the project is to create an innovative STEM curriculum for teachers. The research question from the project was to determine the aspects of the BOP-CCERS project that had a positive influence on underrepresented students' motivation and preparation to pursue STEM careers, compared to other students. A key outcome is to encourage students from underrepresented backgrounds to pursue STEM courses and majors throughout their education, and hence pursue a STEM-based career, which means providing programming and educational 
experiences that motivate student interest in STEM that helps to diversify STEM careers in the United States.

The study found that after engaging students and teachers in the project's STEM activities, URM students had higher levels of interest in STEM and science than did the non-URM students. This is in agreement with previous initiatives reported in literature where exposure to STEM activities in high school provides interest for students to pursue STEM careers (Kitchen, Sonnert, \& Sadler, 2018; Mohr-Schroeder et al., 2014; Roberts et al., 2018; Rohrbaugh \& Corces, 2011). This means that programs should aim to engage URM students with real-world science and mathematics coupled with mentoring from STEM professionals who themselves come from diverse backgrounds. The authors recommend projects, activities, and mentoring designed to build URM student confidence while providing opportunities and guidance designed to help them become aware of their options in STEM education and within STEM careers.

Providing the support services that underrepresented students require in STEM Education was also a key element in the project work over the last seven years. Mentoring, Summer STEM Institutes in Coding, computational thinking, software design, computer science and information systems, and other STEM programs have provided a year round experience and afterschool programs that ultimately give students the necessary resources, tools, and training in STEM education needed to be successful. Teacher professional learning seminars and teacher/scientists designed curriculum also provided both in the field and in classroom experiences that ignite student interest in STEM Education. Providing students with systems and structures that will contribute to their overall STEM framework, will assist to ensure student success in the STEM fields.

\section{References}

Bandura, A. (1986). Social foundations of thought and action: A social cognitive theory. Prentice Hall.

Bandura, A. (1997). Self-efficacy: The exercise of control. W. H. Freeman.

Birney, L., Evans, B. R., Kong, J., Solanki, V., Mojica, E.-R., Kondapuram, G., \& Kaoutzanis, D. (2021). Undergraduate and graduate student research in STEM education. Journal of Curriculum and Teaching, 10(1), 29-35. https://doi.org/10.5430/jct.v10n1p29

Birney, L., Kong, J., \& Evans, B. R. (2019). Experiential and Real-World Learning for Teachers in the Billion Oyster Project and Curriculum and Community Enterprise (BOP-CCERS) for the Restoration of New York Harbor with New York City Public Schools Program. Journal of Curriculum and Teaching, 8(4), 30-35. https://doi.org/10.5430/jct.v8n4p30

Brandt, J. (2016). Mathematicians' and math educators' views on “doing mathematics." Problems, Resources, and Issues in Mathematics Undergraduate Studies, 26(8). https://doi.org/10.1080/10511970.2016.1166408

Estrada, M., Burnett, M., Campbell, A. G., Campbell, P. B., Denetclaw, W. F., Gutierrez, C. G., Hurtado, S., John, G. H., Matsui, J., McGee, R., Okpodu, C. M., Robinson, T. J., Summers, M. F., Werner-Washburne, M. W., \& Zavala, M. E. (2016). Improving underrepresented minority student persistence in STEM. CBE Life Sciences Education, 15(3). https://doi.org/10.1187/cbe.16-01-0038

Freeman, S., Eddy, S. L., McDonough, M., Smith, M. K., Okoroafor, N., Jordt, H., \& Wenderoth, M. P. (2014). Active leaning increases student performance in science, engineering, and mathematics. Proceedings of the National Academy of Sciences of the United States of America, 111(12), 8410-8415. https://doi.org/10.1073/pnas.1319030111

Hoskins, S. G. (2019). How I leaned to teach like a scientist. Science. https://doi.org/10.1126/science.caredit.aay3706

Kennedy, T. J., \& Odell, M. R. L. (2014). Engaging students in STEM education. Science Education International, 25(3), 246-258.

Kitchen, J. A., Sonnert, G., \& Sadler, P. M. (2018). The impact of college- and university-run high school summer programs on students' end of high school STEM career aspirations. Science Education, 102(3), 529-547. https://doi.org/10.1002/sce.21332

Martin-Hansen, L. (2018). Examining ways to meaningfully support students in STEM. International Journal of STEM Education, 53. https://doi.org/10.1186/s40594-018-0150-3

Mohr-Schroeder, M. J., Jackson, C., Miller, M., Walcott, B., Little, D. L., Speler, L., Schooler, W., \& Schroeder, D. C. (2014). Developing Middle School Students' Interests in STEM via Summer Learning Experiences: See Blue STEM Camp. School Science and Mathematics, 114(6), 291-301. https://doi.org/10.1111/ssm.12079 
Mokter Hossain, M., \& Robinson, M. G. (2012). How to motivate US students to pursue STEM (Science, Technology, Engineering, and Mathematics) careers. US-China Education Review, 4, 442-451.

President's Council of Advisors on Science and Technology (PCAST). (2010). Prepare and inspire: K-12 science, technology, engineering, and math (STEM) education for America's future. Retrieved from http://stelar.edc.org/sites/stelar.edc.org/files/pcast-stem-ed-final.pdf

Piaget, J. (1971). Psychology and epistemology: Towards a theory of knowledge. Grossman Publishers.

Piaget, J., \& Inhelder, B. (1972). The psychology of the child. Basic Books.

Plank, L. (2017). Getting students excited about STEM. Smartbrief. Retrieve from https://www.smartbrief.com/original/2017/08/getting-students-excited-about-stem

Preininger, A. M. (2018). 4 ways to boost STEM participation in underrepresented groups. STEM for Social Justice, 14(8). Retrieved from http://www.ascd.org/ascd-express/vol14/num08/4-ways-to-boost-stem-participation-in-underrepresented-groups .aspx

Roberts, T., Jackson, C., Mohr-Schroeder, M. J., Bush, S. B., Maiorca, C., Cavalcanti, M., \& Cremeans, C. (2018). Students' perceptions of STEM learning after participating in a summer informal learning experience. International Journal of STEM Education, 5(1), 35. https://doi.org/10.1186/s40594-018-0133-4

Rohrbaugh, M. C., \& Corces, V. G. (2011). Opening Pathways for Underrepresented High School Students to Biomedical Research Careers: The Emory University RISE Program. Genetics, 189(4), 1135-1143. https://doi.org/10.1534/genetics.111.132126

Salto, L. M., Riggs, M. L., Delgado De Leon, D., Casiano, C. A., \& De Leon, M. (2014). Underrepresented minority high school and college students report STEM-pipeline sustaining gains after participating in the Loma Linda University Summer Health Disparities Research Program. PLoS One, 9(9), e108497. https://doi.org/10.1371/journal.pone.0108497

Theobald, E. J., Hill, M. J., Tran, E., Agrawal, S., Arroyo, E. N., Behling, S., Chambwe, N., Cintrón, D. L., Cooper, J. D., Dunster, G., Grummer, J. A., Hennessey, K., Hsiao, J., Iranon, N., Jones, L., Jordt, H., Keller, M., Lacey, M. E., Littlefield, C. E., Lowe, A., Newman, S., Okolo, V., Olroyd, S., Peecook, B. R., Pickett, S. B., Slager, D. L., Caviedes-Solis, I. W., Stanchak, K. E., Sundaravardan, V., Valdebenito, C. Williams, C. R., Zinsli, K., \& Scott Freeman, S. (2020). Active learning narrows achievement gaps for underrepresented students in undergraduate science, technology, engineering, and math. Proceedings of the National Academy of Sciences of the United States of America, 117(12), 6476-6483. https://doi.org/10.1073/pnas.1916903117

Vygotsky, L. S. (1987). Thinking and speech. In R. W. Rieber \& A. S. Carton (Eds.), The Collected Works of Vygotsky, L. S., 1. Problems of general psychology, 39-285. Plenum.

Wilcox, J., Kruse, J., \& Clough, M. (2015). Teaching Science through Inquiry. The Science Teacher, 62-67. http://doi.org/10.2505/4/tst15_082_06_62

\section{Copyrights}

Copyright for this article is retained by the author(s), with first publication rights granted to the journal.

This is an open-access article distributed under the terms and conditions of the Creative Commons Attribution license (http://creativecommons.org/licenses/by/4.0/). 